\title{
Energy saving strategies for technology-rich learning environments
}

\author{
S. K. Elmasry \\ Department of Architectural Engineering, College of Engineering, \\ United Arab Emirates University, United Arab Emirates
}

\begin{abstract}
Learning environments today are expected to host multiple technologies efficiently, to adapt to the fact that such technologies are more demanding spatially, financially and transforming educational facilities into energyconsumers. Solutions to this problem can be compensated by space design and systems' integration, which address embedded energy loads in facility design and operation. This study addresses the role that the integrated design of learning environments plays in reducing energy consumption within the facility.

The study is qualitative in nature, and based on data gathered from a sample of teachers at the Governor's science and technology schools in the state of Virginia, U.S.A. The data sets capture problems and challenges related to occupants' performance within the classroom when learning technologies are in use.

Two sets of design strategies are identified on two levels; the facility planning and the operational levels. Both sets are communicated in the form of design patterns. If implemented during the decision making phase, these patterns potentially reduce embedded energy in the design, construction and operation processes of contemporary technology-rich educational facilities.
\end{abstract}

Keywords: energy consumption, learning environments, learning technologies, performance-based design.

\section{Introduction}

Contemporary pedagogical approaches and their current technological needs have challenged classroom design to meet students' diverse learning styles and teachers' pedagogical practices. 
Through the implementation of performance-based design and building systems' integration, this study proposes that total embedded energy can be significantly reduced at the design, planning and operational levels of such facilities.

It is widely accepted that systems' integration is a vital part of intelligence in buildings [1]. Bachman [2] also suggests that the counter-position of seeing integration as just another word of design is worth pondering. By adopting a systems' integration approach in general, designers and decision makers will gain an awareness of the interrelated nature of the choices or decisions involved; be able to recognize and choose patterns or change them, the result is proven energy, cost and time savings [3].

These savings take place at multiple levels; the first is the facility planning level as relates to technology integration within the space and whole space design. Second, the operational which relates to performance of space occupants and their spatial requirements. Finally, the environmental level as relates to the built environment in a more comprehensive way. This study investigates potential energy savings in such spaces at both the facility planning and operational levels.

In order to gain a better understanding of the nature of learning environments and patterns within them, it is important to define their components. Figure 1 illustrates the four components of learning environments as proposed in this study. These are learning technologies, pedagogical practices, the physical environment and the architectural systems within the space and finally, space occupants and issues related to their productivity, safety, and comfort. These components are related in multiple ways and directly influence space design.

In addition to the fact that learning technologies are direct consumers of energy, energy savings can be achieved by proper integrated design for location, circulation and communication with these technologies. Figure 2 illustrates data collected from participants regarding learning technologies in their spaces.

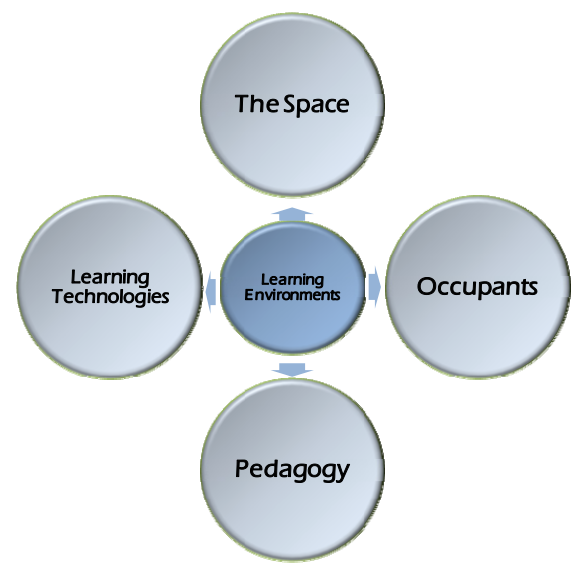

Figure 1: $\quad$ Four components of learning environments. 
On the other hand, the study of learning environments in this research is directly correlated with the pedagogical practices taking place within them. Figure 2 illustrates a spectrum of these models as proposed in the literature [4]. Classification of any teaching-learning practice within this spectrum depends on the extent to which a teacher directly leads the student versus promoting activities through which students can develop valuable reasoning skills. Figure 4 illustrates the distribution of the research sample along this spectrum.

The educational environment is also an active and social one, which demands a multidisciplinary setting with high communication potential. Spatially, a number of issues should be taken into consideration. For example space definition, layout, zoning, flexibility, adaptability of the space to different activities, future technological changes, connectivity to the outdoors, multiuse, support spaces and integration among different systems and learning technologies. Design of the acoustical, thermal, and visual environments is also major issues when we deal with energy consumption in the space.

Change in energy performance of learning spaces is controlled in part by teacher belief systems that limit the number of possible options for change. Thus, learning environments which supported new teaching models have always encountered performance failures since teachers usually resisted everything new that the classroom space presented $[5,6]$.

Technology and the physical environment should still support this change by providing individualized, small team, as well as group instruction and giving students the opportunity to progress at their own pace.

This study assumes that how teachers and students interact with each other and with learning technologies highly influence decisions of integrated, energy efficient design.

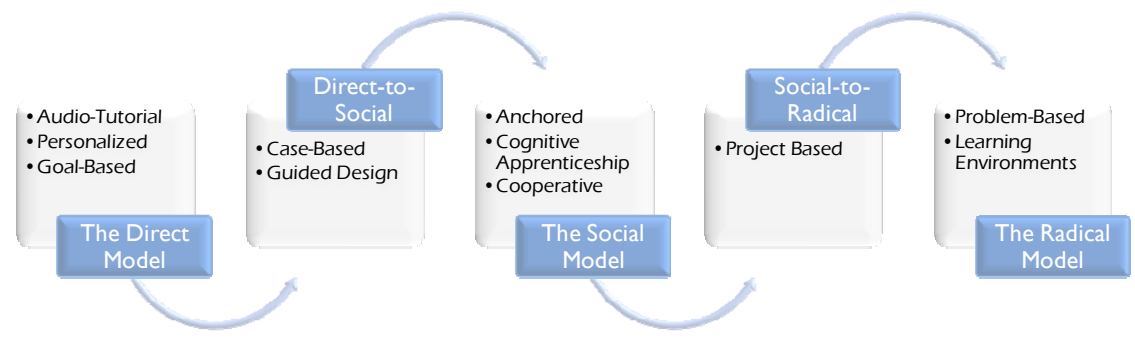

Figure 2: A spectrum of pedagogical models.

\section{Research design}

This study is qualitative in nature and is based on data gathered from teachers at three Academic-Year Governor's schools and one Science and Technology school in Virginia, U.S.A.

The sample of participating teachers is diverse as well as the disciplines they teach which include sciences, mathematics, computer science, aviation, scientific 
research, environmental and natural resources, health and human services, as well as engineering and architecture, as illustrated in Figure 3.

Through multiple data gathering techniques as illustrated in Figure 4, different pedagogical practices were identifiable, as well as data regarding the availability of learning technologies, and patterns of space use.

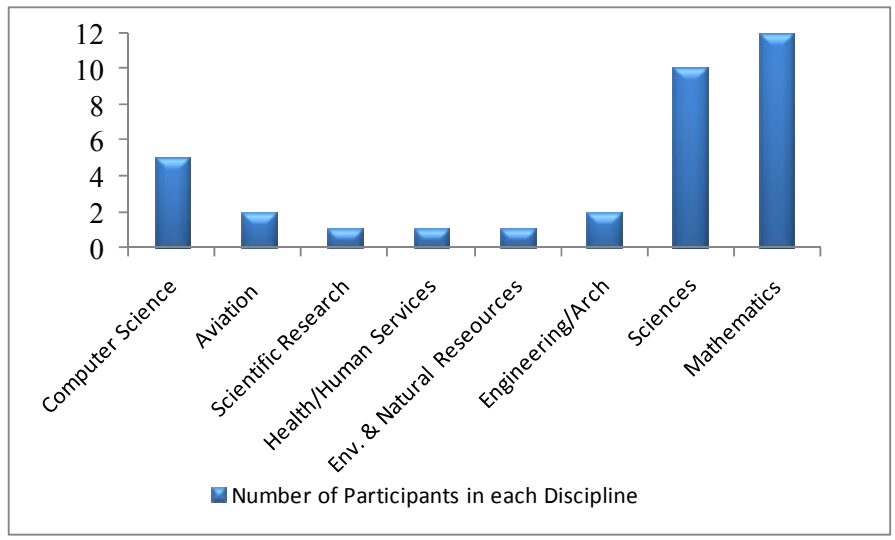

Sciences include anatomy, physiology, chemistry, biology and earth sciences

Figure 3: Distribution of research sample according to discipline.

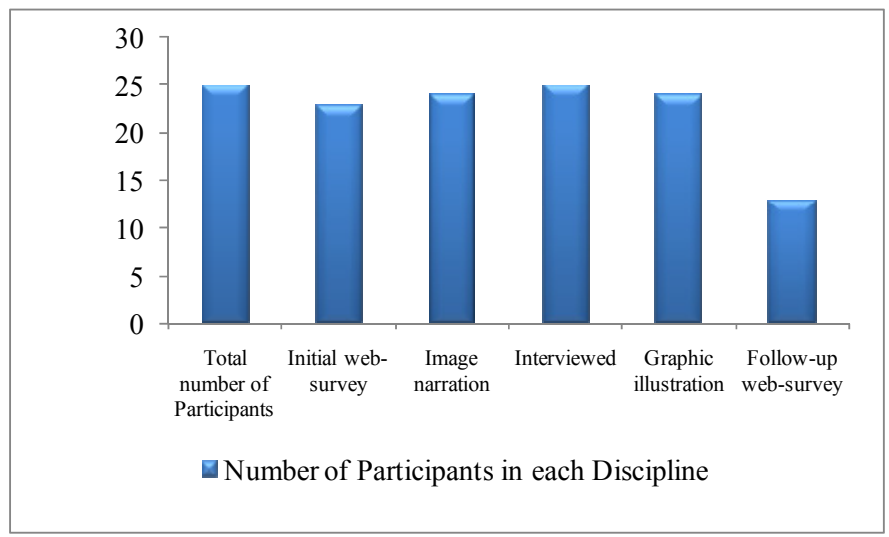

Figure 4: Number of responses of data gathering modes.

Data collected from participants is organized into data matrices to form smaller chunks of data. These matrices reflect the four components of learning environments; pedagogy, technology, space, and the occupants. Participants were also classified according to their teaching style for data reduction. 
Design patterns emerged through two iterations of coding of qualitative data sets. These patterns represent design decisions which incorporate energy saving strategies at both the planning and operational levels of learning environments.

\section{Design for energy saving}

The study concludes two sets of design patterns. They investigate two levels of the building life cycle; the planning and the operational levels.

\subsection{The planning level}

Integrating technologies in a contemporary learning environment requires attention to the pre-design of space and locations designated to host them. Planning for energy savings can take place through an informed design process. Through qualitative analysis of data, the following general themes are identified.

\subsubsection{Physical conditions of the space}

One of the major aspects of space planning in a technology-rich contemporary learning environment is the physical conditions of the space; these are represented in lighting, acoustical and thermal conditions.

Participating teachers mostly reflect on visual and lighting conditions in the space. They express their desire to have some degree of controlled lighting conditions in their rooms. A chemistry teacher captures a window in her chemistry lab in Figure 5 and explains the situation saying "when it gets afternoon I have to close the blinds, even if I've opened them in the mornings. For me looking this way at the students, if I'm up at the board and stuff, it's a glare for me; it bothers me... And not so much I guess the students, but then it also creates a glare on the board-the smartboard or the board. Or if you're looking at a video you pretty much have to close it too".

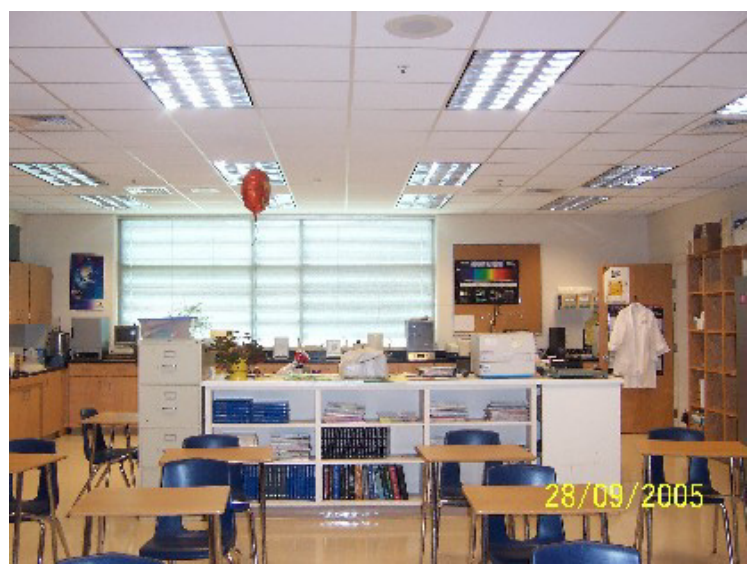

Figure 5: $\quad$ Position of background window as a light source. 
Distribution of lighting over the surface of a learning technology is another issue which emerges repeatedly in the data. A mathematics teacher installs a track light over the white board for even lighting distribution as she captures in Figure 6. She explains saying "I installed the track lighting. I made a special request and I installed that because I've got dead spots on my board that even on the brightest day, it's hard to see. It looks like my board is shaded right there. It's a temporary fix; it's not great. But it does the job".

Having controlled lighting conditions in the learning environment is critical due to the high variation in activities and the need for different lighting levels to match different tasks taking place in the room. Figure 7 represents the proposed pattern formulation.

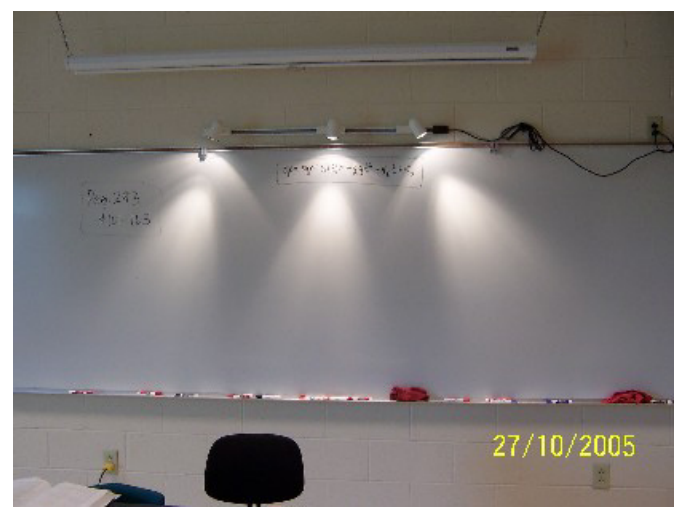

Figure 6: Track lighting installed by mathematics teacher.

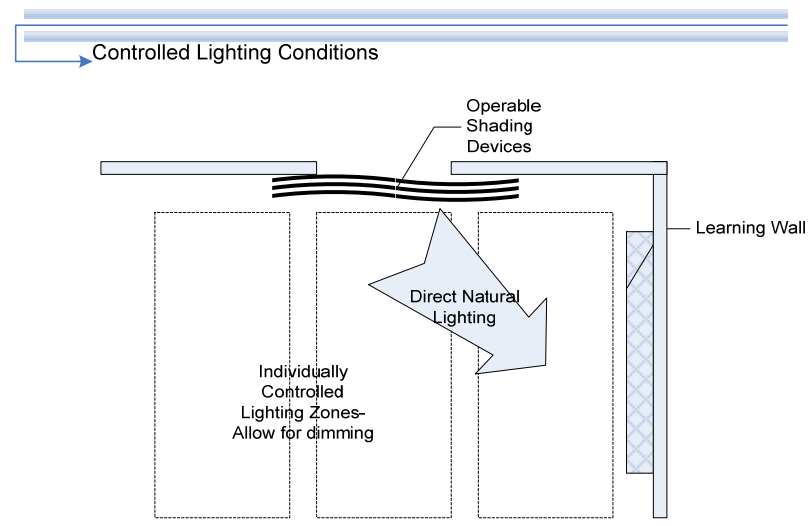

Theme Three- Position and Location of Learning Technologies

Figure 7: $\quad$ Pattern 1: controlled lighting conditions. 


\subsubsection{Integrated design}

Integration of learning technologies in the classroom space as an after-thought can cause conflicts between technologies and space components and may create obstacles in the room, or lack of proper-use of these technologies in the teachinglearning process. This directly influences the level of users' productivity.

At different levels, integration of learning technologies is consciously or unconsciously encouraged by research participants. In Figure 8, a biology teacher graphically explains how technology, the architectural component and the teaching-learning process should be highly integrated for raising the productivity levels and the quality of the process.

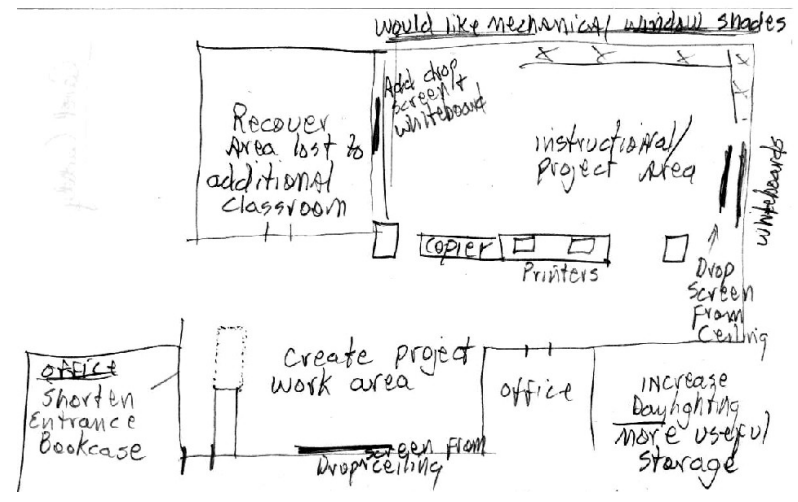

Figure 8: Integrated design of the learning space.

\subsubsection{Location of technologies}

A number of variables are involved in locating learning technologies such as distance, height, angle of inclination, and ergonomics. As an example of these aspects, a mathematics teacher expresses a problem with the location of her TV screen saying "My TV sits so close against the wall that it doesn't turn; it doesn't swivel. So there's no point in it being mounted on a swivel. But I've never had to use it as part of a lesson." She captures this situation in Figure 9.

Decisions regarding integrating learning technologies with the wall plane in the space should consider visual performance of occupants as relates to height and angle of inclination and mounting location in relation to furniture layout. Figure 10 illustrates pattern formulation.

\subsection{The operational level}

Operating the teaching-learning process using different technologies is energy demanding by nature. In addition, productive occupants' performance is essential in terms of increasing occupants' productivity. The study concludes the following design patterns at the operational levels. 


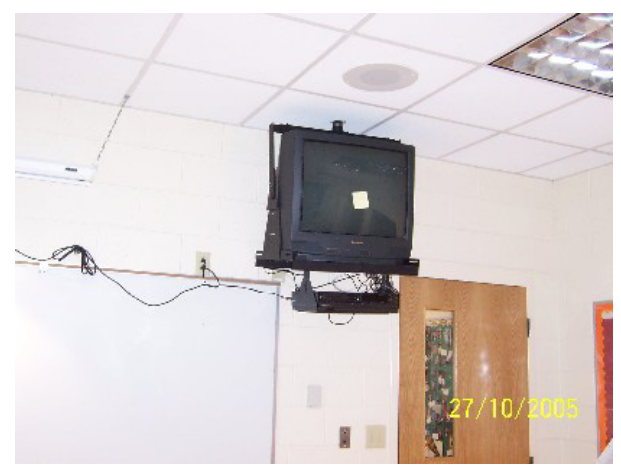

Figure 9: TV screen mounted on a swivel against wall- image captured by mathematics teacher.

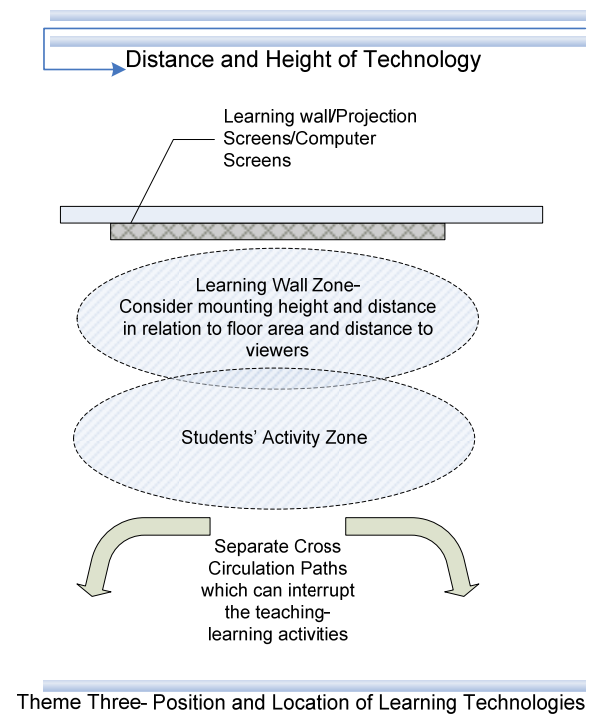

Figure 10: Pattern 2: distance and height of technology.

\subsubsection{Communication within the space}

This pattern specifically points out the possibility for teachers and students to communicate within the space either physically, visually or remotely.

Planning for direct circulation and visual access to learning technologies is highly required by participating teachers. In addition to meeting pedagogical and visual performances of space occupants, this strategy saves energy embedded in the construction process and increases occupants' productivity levels. A chemistry teacher prefers physical presence between the students rather than being tied to a front board. She says "I'm always walking around the room, and come back up here and the board... I like open between me and the students... That way, when you're walking around you can see what they're doing". 
A mathematics teacher mentions that "[students] have a horrible time if they are sitting on this side... because of the TV. When they put up the TV there was no place to put it, they couldn't block the closets on the right or the door on the left, they only could put it over here, which blocks the board," as she captures in Figure 11. Figures 12 and 13 illustrate pattern formulation.

\subsubsection{Monitoring}

Some of the layouts which teachers choose for their learning environments are primarily derived by their need to monitor their students' activities on the computer terminals.

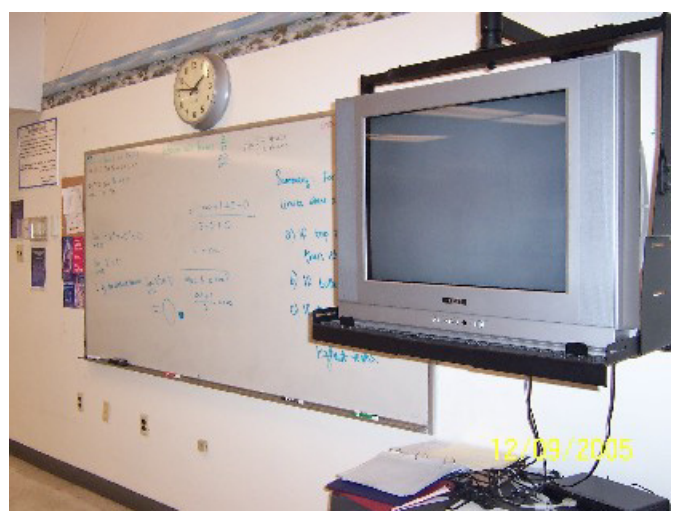

Figure 11: TV screen as a visual obstacle.

Physical Access to Fixed Technologies

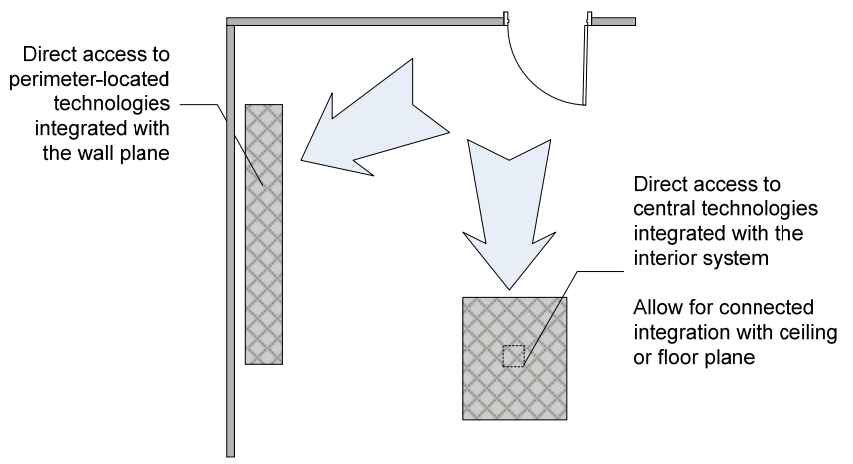

Theme One- Accessibility and Communication

Figure 12: Pattern 3: physical access to technologies. 


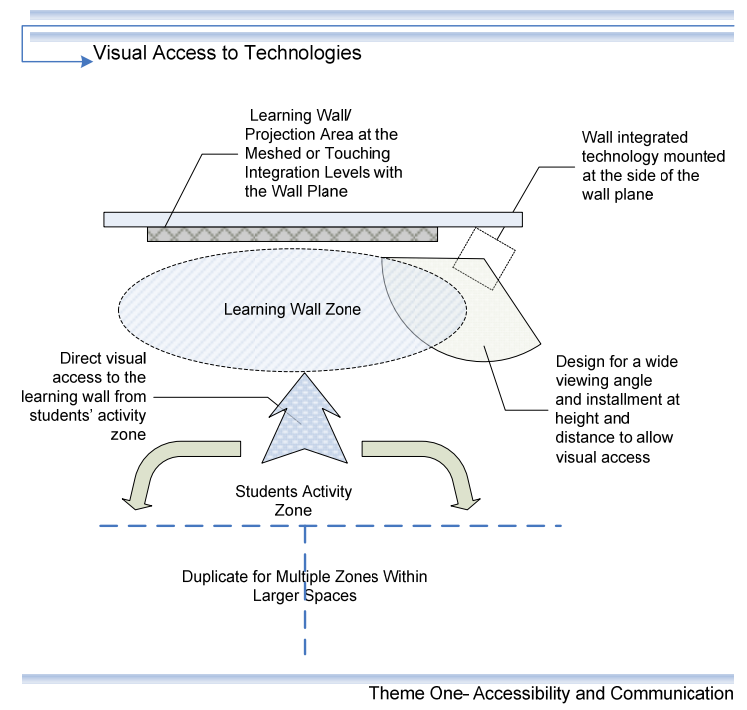

Figure 13: Pattern 4: visual access to technologies.

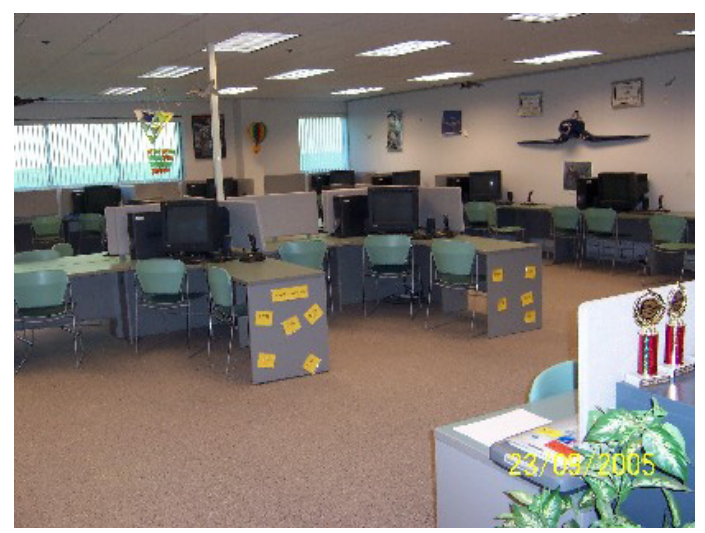

Figure 14: Layout of students' computer stations to enable monitoring.

Integrating students' computer stations with the wall or floor planes and through the furniture system at the room perimeter is one of the most occurring design decisions derived from the need for monitoring.

A teacher explains his experience with the layout of his aviation lab saying "Last summer, I redesigned all of this [the computer stations area] so you can stand over here to see every monitor, all of them at one stop, " He captures this in Figure 14. 


\subsubsection{Mobility}

Most teachers mention that they are moving more towards using laptop computers due to the availability of wireless technology. Furniture systems are also altered; desk-top perimeter stations can thus be replaced with more mobile furniture units to allow for free flow inside the space.

A mathematics teacher prefers moving some of the learning technologies around the room. She captures that in Figure 15 and further explains saying "I've got my smart board here. You have to pull the computer out. I actually prefer that because then I can move the computer around, I can project wherever I want. If it's fixed it just has to point right at the smart board. I don't feel like I use it enough to warrant paying to have it mounted. I can pull it out and use it when I need it...I use the board most often". Figure 18 represents pattern formulation.

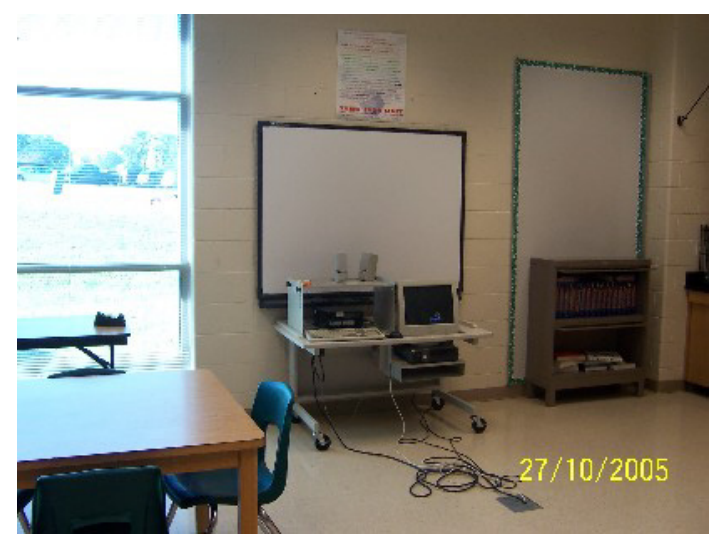

Figure 15: Mobility of technologies in the room.

\section{Conclusion}

Technology-rich learning environments are in nature energy consumers. Through a qualitative analysis process, the study proposes sets of design patterns which are visually communicated with designers and decision makers in the facility planning process. They also respond to occupants' performance within the spaces. The proposed patterns develop on the performance-based design approach as well as the systems' integration approach. They generally address two levels; the planning and the operational.

Within the planning level, three design patterns emerge: physical conditions of the space, integrated design and location of technologies. At the operational level, three other patterns emerge, these are communication within the space, mobility and monitoring. Code mapping for the qualitative analysis process is illustrated in Figure 16.

If consciously implemented in the decision making phase, such patterns potentially lower energy embedded in the design, construction and operation of educational facilities. 


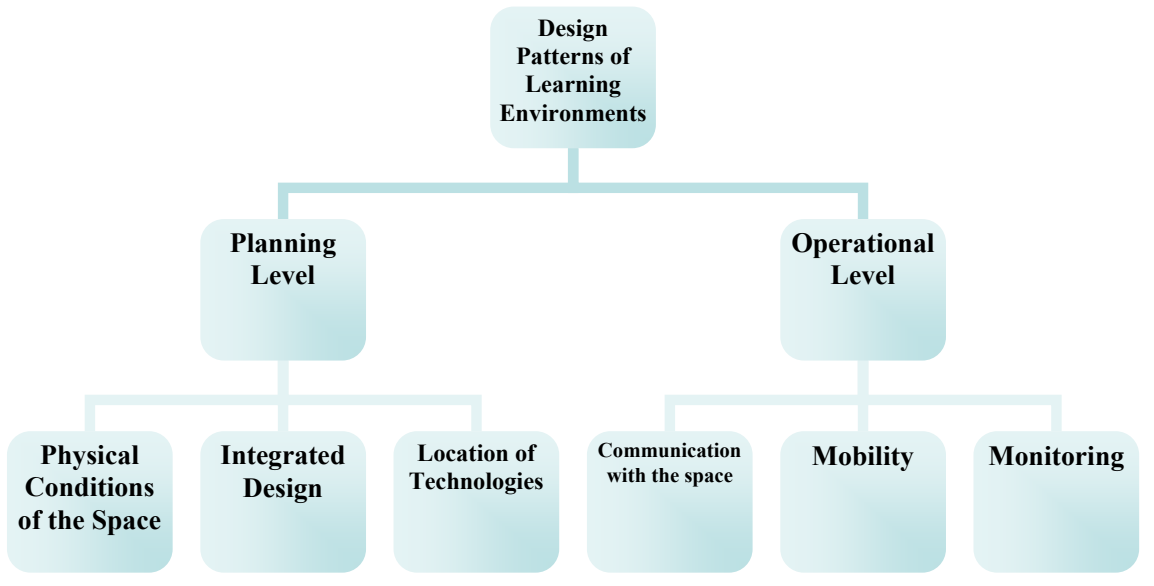

Figure 16: Code mapping for design patterns of learning technologies.

\section{References}

[1] Arkin, H. \& Paciuk, M., Evaluating intelligent buildings according to level of services systems integration. Automation in Construction, $6(\mathbf{5 / 6})$, pp. 471-479, 1997.

[2] Bachman, L.R., Integrated Buildings: the Systems Basis of Architecture, John Wiley \& Sons: New York, 2003.

[3] Rush, R. D. (ed.), The building systems integration handbook, John Wiley \& Sons: New York, 1986.

[4] Davis, B., Sumara, D. \& Luce-Kapler, R., Engaging minds: Learning and teaching in a complex world. London: Lawrence Erlbaum Associates: London, 2000.

[5] Ehrenkrantz, E. D., Planning for Flexibility, Not Obsolescence. Keynote address of the UEF-21 Conference. http://www.designshare.com/ Research/EEK/Ehrenkrantz1.htm, 1999.

[6] Brubaker, C. W., Planning and Designing Schools, McGraw Hill: New York, 1998. 